\title{
A Quick and Simple In-house Screening Protocol for Cold-Tolerance at Seedling Stage in Rice
}

\author{
Hasina Khatun ${ }^{1}$, Partha S Biswas ${ }^{1 *}$, Hung Goo Hwang ${ }^{2}$, Kyung-Min Kim $^{3} *$ \\ ${ }^{1}$ Plant Breeding Division, Bangladesh Rice Research Institute, Gazipur 1701, Bangladesh \\ ${ }^{2}$ Department of Farm Management, Kyungpook National University, Daegu 41566, Korea \\ ${ }^{3}$ Division of Plant Biosciences, School of Applied Biosciences, College of Agriculture \& Life Science, Kyungpook National \\ University, Daegu 41566, Korea
}

\begin{abstract}
Cold stress is an emerging threat for rice production in Bangladesh particularly in Boro season (winter rice) at seedling stage. Cold stress during seedbed stage or early establishment stage at the main field induces severe seedling mortality that increases cost cultivation and delays crop establishment and ultimately entails into low yield. Development of sustainable cold tolerant high yielding rice varieties warrants an efficient and economic screening technique of germplasms and breeding population. The protocols for cold screening that so far have been used by the breeders and reported in literature are generally dependent on natural cool temperature and/or expensive climate chamber. In this paper, we report an in-house screening protocol that requires less than three weeks to complete the screening cycle and can be used all year round for mass screening of breeding population.
\end{abstract}

Keywords Cold stress, Boro season, Seedling, Climate chamber, Rice

\section{INTRODUCTION}

Rice is the staple food for more than half the world's population and is extensively grown by more than half of the world's farmers (Fairhurst and Dobermann 2002; Shelton et al. 2002). Although originating in swampy areas of the tropics, rice is now grown globally in diverse ecologies and thus suffers a wide range of abiotic stresses. Low temperature or cold is a worldwide problem limiting rice yield. There are two types of cold stress in rice. Heading-delay type occurs at young vegetative stage, which results in low spikelet fertility, spikelet-sterility type occurs at reproductive stage, which result in poor grain filling of rice crop (Andaya and Tai 2006). In Bangladesh, around 2 million ha of rice area becomes affected by low temperature during winter season causing seedling mortality in some years up to $90 \%$ and thereby increases cost of cultivation. Rice genotypes differ considerably in cold tolerance (Mackill and Lei 1997). Indica rices those are widely grown in South Asia are very much susceptible to cold stress. The development of high-yielding, cold-tolerant cultivars is the most efficient way to overcome the problem of low-temperature stress. Progress with respect to the improvement of cold tolerance in rice has been so far made using phenotypic selection and conventional breeding strategy (Lovegrove and Wheeler 2008). Considerable efforts have meanwhile been taken to genetically dissect rice cold tolerance using DNA markers, resulting in the discovery and mapping of many quantitative trait loci (QTLs) associated with rice cold tolerance (Misawa et al. 2000; Qian et al. 2000; Andaya and Mackill 2003; Han et al. 2004; Zhang et al. 2005; Han et al. 2007; Lou et al. 2007; Jiang et al. 2008; Iwata et al. 2010; Ji et al. 2010). Unfortunately, results from these genetic studies have not been directly applicable to marker-assisted selection for improvement of cold tolerant

Received July 16, 2016; Revised August 13, 2016; Accepted August 19, 2016; Published August 31, 2016

*Corresponding author Partha S Biswas, psbiswasbrri@yahoo.com, Tel: +880-2-9294117-21, Fax: +880-2-9261110 Kyung-Min Kim, kkm@knu.ac.kr, Tel: +82-53-950-5711, Fax: +82-53-958-6880

*These authors contributed equally to this paper as co-corresponding authors. 
rice owing to possible epistasis and gene $\times$ environment interactions associated with the identified QTLs (Hospital 2009). Furthermore, screening protocols for cold tolerance used in those studies were mostly dependent on natural chilling temperature or expensive instruments like climate chamber. Sustainable and economic screening protocol for cold tolerance is therefore essential to dissect gene/QTLs as well as for the development of cold tolerant rice variety. Cold screening in the sub-tropical countries like Bangladesh depends on natural chilling temperature of winter season. The minimum and maximum air temperature in winter season usually prevails between $8^{\circ} \mathrm{C}$ to $12^{\circ} \mathrm{C}$ and $19^{\circ} \mathrm{C}$ to $22^{\circ} \mathrm{C}$, respectively. However, time of onset, duration and intensity of cold spell are in fact unpredictable. Under such situation, cold screening depending on natural cold temperature is not so effective and it cannot be continued round the year. On the other hand, climate chambers are expensive instruments and not suitable for mass screening of breeding population due to volume limitation. In this paper, we report a first in-house, simple, rapid and effective cold tolerance screening protocol that can be used whole the year for discriminating cold tolerant genotypes from intolerant ones.

\section{MATERIALS AND METHODS}

Twenty-four BRRI developed rice varieties were evaluated using differential temperature in a cold water tank

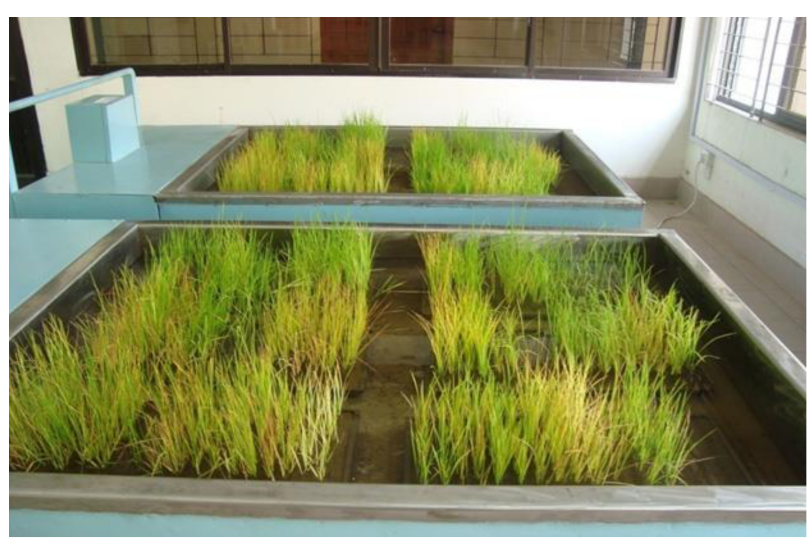

Fig. 1. Screening of rice genotypes for cold tolerance using cold water tank.
(Fig. 1) that was manufactured locally in Bangladesh using simple refrigeration technology (H.G. Hwang's personal communication). The temperature in this tank could be adjusted to a range from $8^{\circ} \mathrm{C}$ to $20^{\circ} \mathrm{C}$. Water temperature in this tank is maintained using a control panel equipped with a sensor. Seedlings were raised in plastic trays with a size of $60 \times 30 \times 2.5 \mathrm{~cm}$, which were filled with crop residue and gravel free soil under ambient temperature. The trays accommodated four entries each with six rows. The seedlings were allowed to grow until 3-leaf stage (10-12 days) and then the trays were placed into the cold water tank. Two cold water tanks adjusted to a constant temperature of $10^{\circ} \mathrm{C}$ and $13^{\circ} \mathrm{C}$ were used for this experiment. Water temperature was conceived based on the empirical rule of thumb that there will be $3^{\circ} \mathrm{C}$ less temperature in ambient compared to water in a given environment. Six trays containing 24 varieties were placed in each tank. The depth of water in the tank was maintained at $5 \mathrm{~cm}$, and seedlings were treated for 8 days at low temperature. In this experiment, only the water temperature was controlled, and air temperature and humidity were not controlled. Leaf discoloration (LD), survival rate and recovery rate are the most commonly used selection criteria in screening of rice plants against cold stress at seedling stage. In this experiment, LD was considered for the estimation of cold tolerance. In order to determine the proper temperature condition and scoring date that would enable the easy differentiation of the genotypes, LD scoring was done from 1st day to last day of cold water treatment using a scale of 1 to 9 according to the method of IRRI SES (1-3: tolerant, 7-9: susceptible) as give below. The same experiment was repeated twice further to consider them as the 2 nd and 3rd replication of the experiment.

\section{LD scale}

0-1: No damage to leaves, normal leaf color (strongly tolerant)

2-3: Tip of leaves slightly dried, folded and light green (tolerant)

4-5: Some seedlings moderately folded and wilted, 30\% to $50 \%$ seedlings dried, pale green to yellowish leaves (moderately tolerant)

6-7: Seedlings severely rolled and dried; reddish-brown 
leaves (sensitive)

8-9: Most seedlings dead and dying (highly sensitive)

\section{RESULTS}

Varietal mean, range, standard deviation (SD) and coefficient of variation calculated for each day of scoring showed no differences between the treatments in mean LD value except on day 8 . However, grand mean $\mathrm{LD}$ value at $13^{\circ} \mathrm{C}$ was less than that at $10^{\circ} \mathrm{C}$ (Table 1$)$. Although LD values in both treatments lay in the same range, $\mathrm{SD}$ and coefficient variation $(\mathrm{CV})$ of interaction effect of variety and days of treatment (variety $\times$ days of treatment) at $13^{\circ} \mathrm{C}$ treatment were higher than at $10^{\circ} \mathrm{C}$. Table 1 also showed that $L D$ values had the lowest range at day 1 and the highest at day 6 , day 7 , and day 8 of cold water treatment. The largest SD was at day 6 scoring, and minimum was observed at day 1 scoring for both the $10^{\circ} \mathrm{C}$ and $13^{\circ} \mathrm{C}$ treatments. On the other hand, the lowest $\mathrm{CV}$ was observed at 1 day after treatment, while it was higher at $10^{\circ} \mathrm{C}$ on day 6 and at $13^{\circ} \mathrm{C}$ on day 5 .

Table 2 shows that BR12 (SD: 1.8), BR9 (1.9), BR18 (1.6), BR26 (1.8), BRRI dhan27 (1.6), and BRRI dhan55 (1.8) had the minimum average LD values ranging from 1-3 and minimum SDs ranging from $1.1-2.0$ at $10^{\circ} \mathrm{C}$ cold water treatment. BR17, BRRI dhan 36 and BRRI dhan 45 also had LD scores of 3 or below but SDs were much higher (2.1-3.0). On the other hand, BR1 had higher average LD score (Table 2) coupled with higher SD.

Varietal discrimination with $13^{\circ} \mathrm{C}$ treatment (Table 3) shows that 12 varieties had an LD score of 3 or below, of

Table 1. Varietal average, range, standard deviation (SD) and coefficient of variation (CV) for leaf discoloration score between the cold water treatments.

\begin{tabular}{|c|c|c|c|c|c|c|c|c|c|}
\hline \multirow{2}{*}{ Treatment } & \multicolumn{8}{|c|}{ Days of scoring (1-9) } & \multirow{2}{*}{$\begin{array}{l}\text { Interaction effect of variety } \\
\times \text { days of treatment }\end{array}$} \\
\hline & I & II & III & IV & $\mathrm{V}$ & VI & VII & VIII & \\
\hline \multicolumn{10}{|l|}{ Average } \\
\hline $10^{\circ} \mathrm{C}$ & 1.0 & 1.2 & 2.0 & 2.97 & 4.0 & 4.8 & 5.9 & 7.5 & 3.7 \\
\hline $13^{\circ} \mathrm{C}$ & 1.0 & 1.3 & 1.8 & 2.7 & 4.0 & 4.5 & 5.6 & 7.1 & 3.5 \\
\hline \multicolumn{10}{|l|}{ Range } \\
\hline $10^{\circ} \mathrm{C}$ & $1-1$ & $1-2$ & $1-4$ & $1-5$ & $2-6$ & $2-7$ & $3-8$ & $4-10$ & $1-9$ \\
\hline $13^{\circ} \mathrm{C}$ & $1-1$ & $1-3$ & $1-4$ & $1-5$ & $1-7$ & $1-8$ & $2-9$ & $4-9$ & $1-9$ \\
\hline \multicolumn{10}{|l|}{ SD } \\
\hline $10^{\circ} \mathrm{C}$ & 0.0 & 0.3 & 0.5 & 0.7 & 1.1 & 1.3 & 1.1 & 0.9 & 2.3 \\
\hline $13^{\circ} \mathrm{C}$ & 0.0 & 0.4 & 0.8 & 1.1 & 1.6 & 1.7 & 1.5 & 1.3 & 2.5 \\
\hline \multicolumn{10}{|l|}{ CV (\%) } \\
\hline $10^{\circ} \mathrm{C}$ & 0 & 24.5 & 22.7 & 24.9 & 26.1 & 27.1 & 18.3 & 12.5 & 61.9 \\
\hline $13^{\circ} \mathrm{C}$ & 0 & 34.1 & 44.6 & 42.0 & 44.1 & 37.5 & 26.9 & 16.8 & 70.3 \\
\hline
\end{tabular}

Table 2. Classification of variety on the basis of standard deviation (SD) and leaf discoloration score at $10^{\circ} \mathrm{C}$ temperature.

\begin{tabular}{clcc}
\hline \hline \multicolumn{1}{c}{ SD } & \multicolumn{1}{c}{$\mathrm{T}^{\mathrm{z})}(1-3)$} & \multicolumn{1}{c}{ MT (4-5) } & $\mathrm{S}(6-9)$ \\
\hline$\leq 1$ & - & - & - \\
$1.1-2.0$ & BR12, BR9, BR18, BR26, & & \\
& BRRI dhan27, BRRI dhan55 & & \\
2.1-3.0 & BR17, BRRI dhan36, BRRI dhan45 & BR2, BR3, BR6, BR7, BR8, BR14, BR15, BR16, & BR1 \\
& & BR19, BRRI dhan28, BRRI dhan35, BRRI dhan50, & \\
BRRI dhan47, BRRI dhan29 & 14 & 1 \\
\hline
\end{tabular}

\footnotetext{
${ }^{\mathrm{z})} \mathrm{T}$ : tolerant, MT: moderate susceptible, S: susceptible.
} 
Table 3. Classification of varieties on the basis of standard deviation (SD) and leaf discoloration score at $13^{\circ} \mathrm{C}$.

\begin{tabular}{|c|c|c|c|}
\hline SD & $\mathrm{T}^{\mathrm{z})}(1-3)$ & MT (4-5) & $S(6-9)$ \\
\hline$\leq 1$ & - & - & - \\
\hline $1.1-2.0$ & BR17, BR18, BR26, BRRI dhan27 & & \\
\hline $2.1-3.0$ & $\begin{array}{l}\text { BR8, BR9, BR12, BRRI dhan } 14 \text {, BR } 15 \text {, } \\
\text { BRRI dhan } 28 \text {, BRRI dhan } 36 \text {, BRRI dhan } 45 \text {, } \\
\text { BRRI dhan } 55\end{array}$ & $\begin{array}{l}\text { BR2, BR6, BR7, BR16, BR19, BRRIdhan29, } \\
\text { BRRIdhan35, BRRI dhan47, BRRI dhan50 }\end{array}$ & $\begin{array}{l}\text { BR1, } \\
\text { BR3 }\end{array}$ \\
\hline Total & 12 & 9 & 2 \\
\hline
\end{tabular}

${ }^{\mathrm{z})} \mathrm{T}$ : tolerant, MT: moderate susceptible, $\mathrm{S}$ : susceptible.

which four varieties viz., BR17 (SD: 1.9), BR18 (1.6), BR26 (1.5), and BRRI dhan27 (1.1) had SD in a range of 1.1-2.0. On the other hand, BR1 and BR3 showed higher average $\operatorname{LD}(6,6)$ coupled with higher $\operatorname{SD}(2.9,3.2)$.

\section{DISCUSSION}

Cold is an emerging problem in rice production in winter season of Bangladesh. Boro rice is badly affected in some years by cold injury during seedling stage. Seedlings get stunted, yellowing and ultimately died due to fungal attack associated with cold stress (Khush and Jena 2009). Cold screening, which is the integral part of development of cold tolerant variety, is mostly dependent on natural cold temperature or expensive climate chamber in tropical countries. For cold screening at seedling stage, seed sowing is usually schedule in such a way that emerging seedling in the seedbed or early establishment stage of crop in the main field are exposed to natural cold temperature in winter season. However, the onset time, span of cold wave and intensity of cold is very unpredictable in Bangladesh. Therefore, natural temperature dependent screening does not reflect true performance many a time. Moreover, screening activities can be performed once a year because of short span of winter season. In this situation, use of in-house cold water tank might increase efficiency of cold screening and can be used round the year for discriminating tolerant genotypes from intolerant ones. The 3-leaf stage of rice plant is the most responsive stage to low temperature. Cold stress at this stage causes stunting growth, yellowing and ultimately death of rice seedlings. Rice root at temperature below $15^{\circ} \mathrm{C}$ becomes malfunctioned due to cessation of hydraulic conductivity and plant suffers from water (Murai-Hatano et al. 2008). Cold treatment to 3-leaf staged rice plants in cold water tank was thus used to develop a simple and quick method of cold screening. Cold treatment to twenty-four varieties with $10^{\circ} \mathrm{C}$ and $13^{\circ} \mathrm{C}$ for differential number days showed the grand mean $\mathrm{LD}$ value at $13^{\circ} \mathrm{C}$ was less than that at $10^{\circ} \mathrm{C}$; however, no significant differences between the treatments in mean LD value was noticed except on day 8. Although LD values in both treatments were in the same range, the SDs and CV values of the interaction effect of variety and days of treatment (variety $\times$ days of treatment) at $13^{\circ} \mathrm{C}$ treatment were higher than at $10^{\circ} \mathrm{C}$. This indicated that $13^{\circ} \mathrm{C}$ treatment was better than $10^{\circ} \mathrm{C}$ treatment for discriminating varieties. On the other hand, the range of LD values was the lowest at day 1 and the highest at day 6 , day 7 , and day 8 of cold water treatment. The largest SD was at day 6 scoring, and minimum was observed at day 1 scoring for both the $10^{\circ} \mathrm{C}$ and $13^{\circ} \mathrm{C}$ treatments. Moreover, the lowest $\mathrm{CV}$ was observed at 1 day after treatment, while it was higher at $10^{\circ} \mathrm{C}$ on day 6 and at $13^{\circ} \mathrm{C}$ on day 5 . Considering the wide range of $\mathrm{LD}$ values, the largest $\mathrm{SD}$ and larger $\mathrm{CV}$, scoring at day 6 after cold water treatment was determined as effective for differentiating and discriminating genotypes for LD. The genotypes, BR12, BR9, BR18, BR26, BRRI dhan27, and BRRI dhan55 showing minimum average LD values (1-3) and minimum SDs (1.1-2.0) at $10^{\circ} \mathrm{C}$ cold water treatment indicated them to be potential cold-tolerant genotypes at seedling stage. On the other hand, BR17, BRRI dhan36, and BRRI dhan 45 had LD scores of 3 or below but SDs were much higher (2.1-3.0), indicating inconsistent cold tolerance. Moreover, BR1 had higher average LD score (Table 2) coupled with higher SD, 
indicating that it was the most susceptible genotype to $10^{\circ} \mathrm{C}$ cold treatment. Furthermore, cold water treatment with $13^{\circ} \mathrm{C}$ (Table 3 ) showed that 12 varieties had an LD score of 3 or below, of which four varieties viz., BR17 (SD: 1.9), BR18 (1.6), BR26 (1.5), and BRRI dhan27 (1.1) had SD in a range of 1.1-2.0. On the other hand, BR1, and BR3 showed higher average LD $(6,6)$ coupled with higher SD $(2.9,3.2)$. These results clearly indicated that BR17, BR18, BR26, BRRI dhan27 had stable tolerance at $13^{\circ} \mathrm{C}$ cold water, but BR1 and BR3 were susceptible to cold damage. However, three varieties, BR9, BR12, and BRRI dhan55 showed variable SD of LD values among the temperature regime indicating genetic instability of these varieties over the changing environment. Considering $L D$ values and $\mathrm{SD}$ at $10^{\circ} \mathrm{C}$ and $13^{\circ} \mathrm{C}$ cold water treatment, BR18, BR26, and BRRI dhan 27 were found to be tolerant and BR1 was found to be most susceptible to cold damage at seedling stage. Based on the above findings it can be concluded that by using cold water treatment at $13^{\circ} \mathrm{C}$ for 6 days, rice genotypes could be assessed effectively and as quickly as in three weeks having cold tolerance at seedling stage. Therefore, this protocol can be used round the year to screen a large number of breeding populations without any dependency on natural cool temperature. This protocol has a great promise for application in screening a large set of rice breeding lines, germplasm and Genebank accessions to identify useful materials for future cold tolerant rice breeding programs. Furthermore, BR18 and BR1 could be used as standard differential varieties in the selection for a seedling LD screening to evaluate national breeding program for cold tolerant rice.

\section{ACKNOWLEDGEMENTS}

We duly acknowledge Korea International Cooperation Agency (KOICA) for financial and technical support for this work through the implementation of project "Development of research capacity of the Bangladesh Rice Research Institute". We also thankful to the Genetic Resources and Seed Division, and Plant Breeding Division, BRRI for sharing seeds of varieties and germplasm used in the study.

\section{REFERENCES}

Andaya VC, Mackill DJ. 2003. Mapping of QTLs associated with cold tolerance during the vegetative stage in rice. J. Exp. Bot. 54: 2579-2585.

Andaya VC, Tai TH. 2006. Fine mapping of the qCTS12 locus, a major QTL for seedling cold tolerance in rice. Theor. Appl. Genet. 113: 467-475.

Fairhurst TH, Dobermann A. 2002. Rice in the global food supply. World 5: 454, 349-511, 675.

Han LZ, Qiao YL, Cao GL, Zhang YY, An YP, Ye JD, et al. 2004. QTL analysis of cold tolerance duri. early growth period for rice. Rice Sci. 11: 245-250.

Han L, Qiao Y, Zhang S, Zhang Y, Cao G, Kim J, et al. 2007. Identification of quantitative trait loci for cold response of seedling vigor traits in rice. J. Genet. Genomics 34: 239-246.

Hospital F. 2009. Challenges for effective marker-assisted selection in plants. Genetica 136: 303-310.

Iwata N, Shinada H, Kiuchi H, Sato T, Fujino K. 2010. Mapping of QTLs controlling seedling establishment using a direct seeding method in rice. Breed. Sci. 60: 353-360.

Ji ZJ, Zeng YX, Zeng DL, Ma LY, Li XM, Liu BX, et al. 2010. Identification of QTLs for rice cold tolerance at plumule and 3-leaf-seedling stages by using QTL network software. Rice Sci. 17: 282-287.

Jiang L, Xun M, Wang JK, Wan JM. 2008. QTL analysis of cold tolerance at seedling stage in rice (Oryza sativa L.) using recombination inbred lines. J. Cereal Sci. 48: 173-179.

Khush GS, Jena KK. 2009. Current status and future prospects for research on blast resistance in rice (Oryza sativa L.), p.1-10. In: G.L. Wang, B. Valent (ed.). Advances in genetics, genomics and control of rice blast disease. Springer, Berlin.

Lou QJ, Chen L, Sun ZX, Xing YZ, Li J, Xu XY, et al. 2007. A major QTL associated with cold tolerance at seedling stage in rice (Oryza sativa L.). Euphytica 158: 87-94.

Lovegrove MB, Wheeler RD. 2008. Barley benefits from grazing. In: M. Unkovich (ed.), Global Issues. Paddock Action. Proc. of the: 14th Agronomy Conference 2008, 21-25 September 2008. Adelaide, Australia.

Mackill DJ, Lei XM. 1997. Genetic variation for traits related to temperate adaptation of rice cultivars. Crop Sci. 37: 
1340-1346.

Misawa S, Mori N, Takumi S, Yoshida S, Nakamura C. 2000. Mapping of QTLs for low-temperature response in seedlings of rice (Oryza sativa L.). Cereal Res. Commun. 28: 33-40.

Murai-Hatano M, Kuwagata T, Sakurai J, Nonami H, Ahamed A, Nagasuga K, et al. 2008. Effect of low root temperature on hydraulic conductivity of rice plants and the possible role of aquaporins. Plant Cell Physiol. 49: 1294-1305.

Qian Q, Zeng DL, He P, Zheng XW, Chen Y, Zhu LH. 2000. QTL analysis of the rice seedling cold tolerance in a double haploid population derived from anther culture of a hybrid between indica and japonica rice. Chin. Sci. Bull 45: 448-453.

Shelton AM, Zhao JZ, Roush RT. 2002. Economic, ecological, food safety, and social consequences of the deployment of Bt transgenic plants. Annu. Rev. Entomol. 47: 845-881.

Zhang ZH, Su L, Li W, Chen W, Zhu YG. 2005. A major QTL conferring cold tolerance at the early seedling stage using recombinant inbred lines of rice (Oryza sativa L.). Plant Sci. 168: 527-534. 